\title{
El grupo de teatro de la Facultad de Medicina y Ciencias de la Salud
}

\section{Grupo de teatro de la Facultad de Medicina y Ciencias de la Salud}

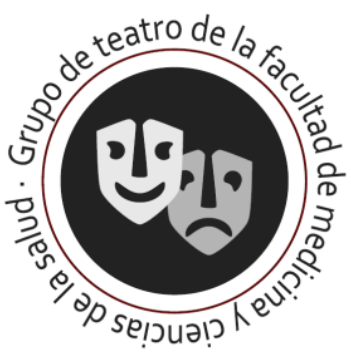

El Grupo de Teatro de la Facultad de Medicina y Ciencias de la Salud lleva formando parte de la Universidad de Alcalá, y del día a día de muchos estudiantes, desde hace ya 29 años. Durante estos años para los estudiantes de medicina, enfermería o fisioterapia ha brindado la oportunidad de conocerse y entablar relaciones, tanto con las personas de su misma titulación como con muchas otras. Esto que podría parecer prescindible dentro en el día a día de un estudiante, supone para muchos, una forma única de enriquecer su paso por la universidad.

Durante los últimos años se ha trabajado con obras muy variadas, siempre sacando el mayor partido al año de ensayos y risas con los compañeros actores. Un ejemplo es la obra realizada en 2016, "El Sueño de una noche de verano", de W. Shakespeare, todo un reto tanto interpretativo como escenográfico. La creatividad de nuestros teatreros fue enorme, y finalmente la obra se estrenó con trabajos increíbles en decoración, coreografía, vestuario, y por supuesto, actuación de todos los personajes.

La representación del curso pasado, "La casa de Bernarda Alba" fue una obra radicalmente distinta a la anterior, y, aun así, un proyecto igualmente interesante. De trama más oscura y dramática, supuso un trabajo intenso en el que todo el grupo se volcó con entusiasmo y dedicación.

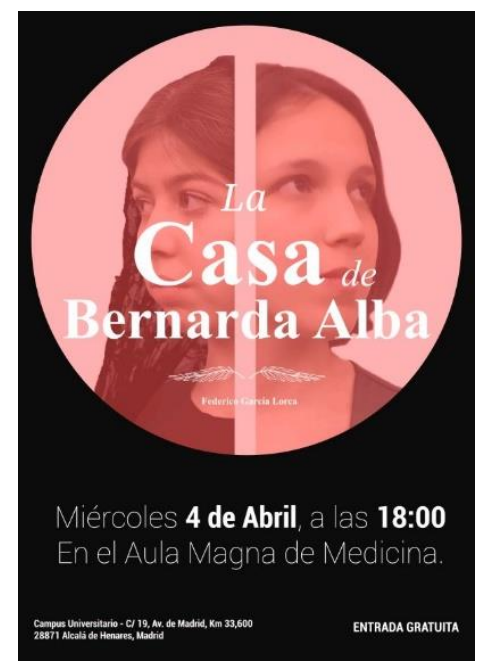

Y tras todo un curso de preparación, dimos vida a una de las tragedias más famosas del teatro español exitosamente, para el entretenimiento de nuestros compañeros, familiares, amigos y profesores, estudiantes y PAS de la facultad.

Este maravilloso grupo teatral surgió gracias al catedrático de traumatología Antonio López Alonso quien en 1990 decidió preparar una obra teatral a modo de despedida con los alumnos de sexto de ese mismo año. Lo que en principio iba a ser una única representación de "Bodas de sangre" acabaría convirtiéndose en un auténtico clásico dos décadas más tarde.

Poco después, el grupo se abriría a todos los cursos y se convertiría en el grupo de teatro de la Facultad de Medicina. Durante años, este médico, que llevaba el teatro en las venas, supo transmitir a 25 generaciones de alumnos su pasión por las artes escénicas y, cada lunes, desde las butacas del aula magna nos acompañaba con su ilusión y despertaba en nosotros las cualidades interpretativas más insospechadas, siempre dándonos espacio para dejar volar nuestra creatividad. Gracias a él y a la construcción de esta familia a la que arropaba, tenemos hoy este espacio para la experimentación, la oportunidad de conocer gente diferente y descubrirnos nosotros mismos más allá de la universidad. 


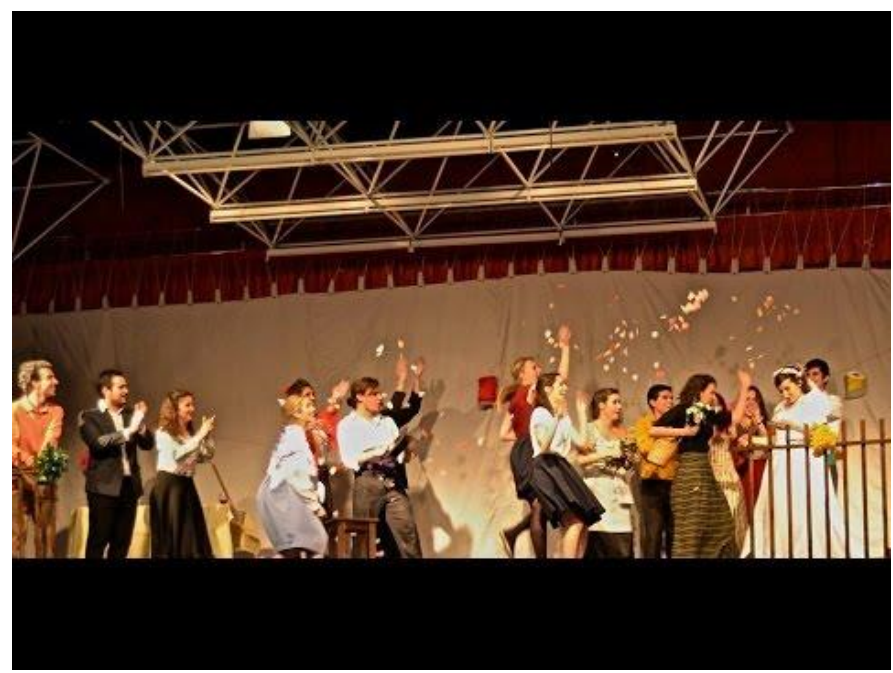

Tras 25 años nuestro querido Antonio nos dejó volar solos. Y ninguna ni ninguno sabíamos el reto al que nos íbamos a tener que enfrentar. No solo nos hemos tenido que ocupar del tema artístico, sino también de toda la burocracia que hay detrás. Estuvimos dos años y medio compartiendo el papel de director entre todos hasta que a mediados del curso pasado llegó Consuelo Giménez, nuestra actual directora.

Con ella terminamos la obra del año pasado y estamos empezando a organizar una nueva para este curso 2018-2019. A pesar de sólo llevar con ella unos pocos meses, agradecemos mucho su ayuda, no solo a nivel burocrático y en la resolución de los problemas que han ido surgiendo, sino también a la hora de dar opiniones y diferentes puntos de vista con respecto a la escena. Ella se declara una firme amante del teatro y las letras y cuenta con mucho camino a sus espaldas en este ámbito, que esperamos seguir andando con ella.

Actualmente nuestra "troupe" está formada por estudiantes de Medicina y esperamos que estos años siguientes podamos seguir compartiendo entre varias ramas sanitarias (Enfermería y Fisioterapia) y de la Facultad (CCAFYDE) nuestras pequeñas pasiones por el arte, la creatividad y el teatro.

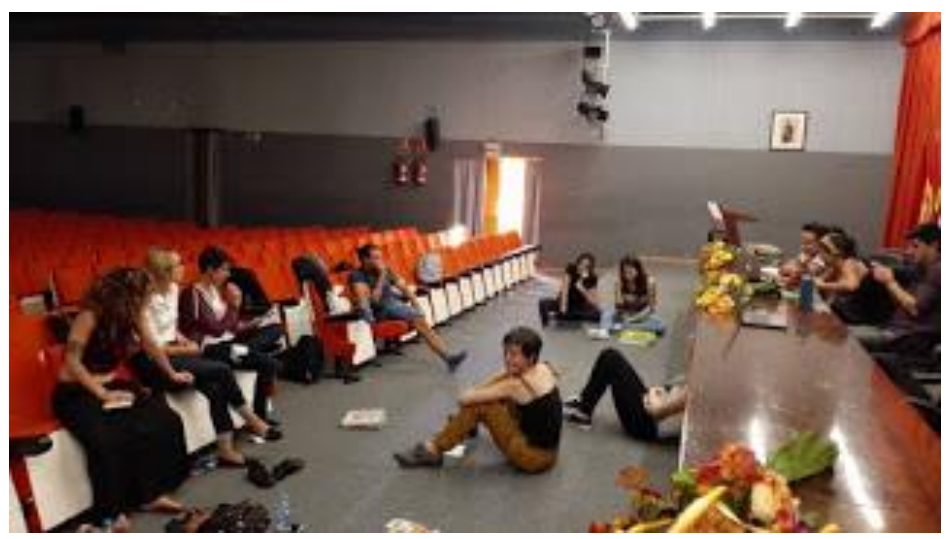

En el primer año de cualquiera, al ser todo novedades, la timidez reina sobre la extroversión, hasta que la situación acaba del revés y el cariño por los compañeros sale solo. Cuando te quieres dar cuenta, estás dentro de una actividad con compañeros universitarios que te suman energía y con los que se genera un vínculo mágico. Cada año trabajado en los distintos géneros, el teatro nos hace sacar el drama, la comedia o la ironía de cada uno, sin olvidar las caras nuevas que llegan y que, con los brazos (y abrazos) abiertos, estamos dispuestos a que en ellos y con ellos también vibre la magia.

Este año estamos dispuestos a afrontar un nuevo reto, alejándonos un poco del dramatismo de la obra anterior. Valoramos obras de misterio como "Diez negritos" de Agatha Christie, comedias como "Usted tiene ojos de mujer fatal" de Poncela o "No te bebas el agua" de Woody Allen. Obras que sin duda alguna acogeremos con entusiasmo y dedicación, y que el año que viene, en marzo o abril, representaremos en el Aula Magna de la Facultad de Medicina y Ciencias de la Salud.

Esperamos que todos los asistentes sientan al verla la misma emoción que nosotros ponemos al prepararla.

(C) 2018 por los autores; licencia MDPI, Basel, Switzerland. Este articulo está distribuido en acceso abierto bajo los términos y condiciones de Creative Commons by Attribution (CCBY) licencia (http://creativecommons.org/licenses/by/4.0/). 